\title{
Motivação discente frente às diferentes composições de turmas (des)seriadas para a Educação Física do ensino médio
}

\section{RESUMO}

A (Des)seriação, proposta de estruturação das turmas para Educação Física do Ensino Médio, foi elaborada com o intuito de motivar os estudantes para as aulas. Neste estudo, do tipo misto, discentes do Ensino Médio, em 2012, 2014, 2015 e 2016, responderam ao questionário Bem Estar Discente na Educação Física acrescido de uma questão aberta. A análise por estatística descritiva e comparação entre grupos revelou que a motivação intrínseca dos estudantes não apresentou diferenças estatisticamente significativas, mas modificou a auto percepção das Necessidades Psicológicas Básicas. Já a análise de conteúdo apresentou visão negativa dos estudantes (54,6\%) relacionada aos Aspectos estruturais do projeto. A crítica relacionada às turmas pares e impares, em 2016, pode ter engessado as escolhas dos alunos e os distanciado de seus objetivos ou interesses, trazendo descontentamento e prejudicando a frequência/permanência discente nas aulas de Educação Física.

PALAVRAS-CHAVE: Educação física; Ensino médio; Motivação

\section{Eduardo Azevedo de Andrade}

Especialista

Universidade Federal do Rio Grande do Sul, Escola Superior de Educação Física,

Fisioterapia e Dança, membro do grupo de Pesquisa Educação e Saúde, Porto

Alegre, Brasil eduardo.andrade@ufrgs.br

https://orcid.org/0000-0002-5911-223X

\section{Carla da Conceição Lettnin \\ Doutora}

Universidade Federal do Rio Grande do

Sul, Departamento de Expressão e Movimento do Colégio de Aplicação, Líder do grupo de Pesquisa Educação e Saúde, Porto Alegre, Brasil lettnin07@hotmail.com 그 https://orcid.org/0000-0002-2807-7961 


\title{
Motivation students in the face of different class composition (un)serial for Physical Education of high school
}

\begin{abstract}
The (Des)serialization, a proposal for structuring classes for Physical Education in High School, was developed with the aim of motivating students for classes. This study - mixed type - students from the High School - in 2012; 2014; 2015 and 2016, completing the questionnaire. The analysis by descriptive statistics and comparison between groups revealed that the students' intrinsic motivation did not show statistically significant differences, but modified the self-perception of Basic Psychological Needs between some years investigated. The content analysis revealed a negative view of the students $(54.6 \%)$ related to the structural aspects of the project. The criticism related to even and odd classes, in 2016, may have plastered the students' choices and distanced them from their goals or interests, bringing discontent and impairing the frequency / permanence of students in Physical Education classes.
\end{abstract}

KEYWORDS: Physical education; High school; Motivation

Motivación de los estudiantes delante de enmiendas de composición de clases (des)serias para la Educación Física en la escuela secundaria

\section{RESUMEN}

La (Des)serialización, propuesta para estructurar las clases de Educación Física en la escuela secundaria, se desarrolló con el objetivo de motivar a los estudiantes para las clases. Los estudiantes de secundaria participaron en este estudio mixto en 2012, 2014, 2015 y 2016. El análisis mediante estadísticas descriptivas y comparación entre grupos reveló que la motivación intrínseca de los estudiantes no mostró diferencias estadísticamente significativas, sino que modificó la autopercepción de las necesidades psicológicas básicas. El análisis de contenido mostró una visión negativa de los estudiantes (54,6\%) relacionada con los Aspectos estructurales del proyecto. La crítica relacionada con las clases pares e impares, en 2016, puede haber enyesado las elecciones de los estudiantes y distanciarlos de sus objetivos o intereses, provocando descontento y obstaculizando la frecuencia de los estudiantes en las clases de Educación Física.

PALABRAS-CLAVE: Educación física; Enseñanza media; Motivación 


\section{AFASTAMENTO dAS AULAS DE EDUCAÇÃO FíSICA E A PROPOSTA DE (DES)SERIAÇÃO}

O propósito desse estudo foi conhecer a motivação dos estudantes dentro de uma proposta diferenciada de organização das turmas de Educação Física (EF) para o Ensino Médio (EM), denominada (Des)seriação, que foi originada a partir da preocupação com aqueles que estavam apresentando uma postura de distanciamento das aulas de EF.

Sabe-se que inúmeros fatores, internos ou externos à escola, podem estar associados e influenciarem no comportamento motivado ou (des)motivado de estudantes frente às propostas pedagógicas. Para subsidiar essa discussão e conhecer possíveis causas que geram o afastamento temporário ou permanente dos alunos das aulas curriculares, especialmente de EF, buscou-se evidenciar alguns indicadores constatados na literatura especializada no tema.

Um dos indicadores apontados e percebidos no ambiente escolar é a falta de relação do que é abordado no EM com a realidade da maior parte dos estudantes. Consequentemente, isso leva à incompreensão deles sobre o real significado daquilo que se estuda e do que se aprende no contexto escolar. Esta falta de sentido, muitas vezes presente no currículo escolar, torna a passagem desta etapa algo meramente obrigatório para essa população. Segundo Pizaniet al. (2016), a escola tem a responsabilidade de proporcionar um ambiente facilitador para que o estudante compreenda a importância do que é ensinado e se sinta motivado a buscar conhecimentos para alcançar seus objetivos.

Outro indicador mencionado pelos autores (PIZANI et al., 2016) está relacionado à forma com que o professor aborda alguns conteúdos. Essas escolhas metodológicas de ensino-aprendizagem podem ser determinantes no sucesso/insucesso do estudante, ou seja, podem influenciar de forma positiva ou negativa a motivação intrínseca (MI) dos alunos.

Investigando essa ausência de motivação no contexto da EF, Darido (2004) afirmou que a falta de desafio nas aulas de EF no EM é um dos principais fatores para o afastamento dos estudantes. Seu estudo revelou que $68 \%$ dos alunos que se afastaram das aulas de EF reportaram que os conteúdos do EM são repetitivos referente aos conteúdos do Ensino Fundamental, não atingindo o interesse da maioria.

Lettnin (2013) acredita que atividades sem sentido ou significado no ambiente escolar, quando forçadas, podem resultar no afastamento dos estudantes. Reforça também que ambientes onde as crianças, adolescentes e jovens são expostos a exigências acima de suas capacidades podem causar mal-estar, resultando em abandono temporário ou permanente. 
Os estudos de Moutão, Alves e Cid (2012), Einsfeldt e Lettnin (2018) eVan der kaap-deederet al. (2018) revelaram que a autopercepção de competência traz muitos benefícios, incluindo bem-estar, persistência e performance. Por outro lado, a frustração com essa variável pode acarretar experiências negativas e, consequentemente, resultar em sintomas depressivos entre outros.

Sabe-se que os alunos que reportam experiências negativas nas aulas de EF ou que têm uma baixa percepção de autoeficácia são aqueles menos ativos dentro e fora da escola (NTOUMANIS, 2005; LETTNIN, 2012; LETTNIN; JESUS; STÖBAUS, 2012). Acredita-se que esse comportamento poderá refletir em outros espaços do ambiente escolar, fazendo com que seu envolvimento com as atividades pedagógicas e com as relações interpessoais sejam infinitamente menor, necessitando ainda mais da intervenção de professores.

O estudo de Brandolin, Koslinski e Soares (2015), realizado na rede estadual do Município de Petrópolis, apontou que 78,2\% dos alunos estão satisfeitos com a EF, porém, existe uma satisfação maior por parte dos estudantes do sexo masculino, com alta habilidade para esportes e que participam do processo de escolha dos conteúdos.

Na opinião de Lettnin (2013), ter alunos motivados nas aulas de EF é fundamental, pois a escola será um dos espaços mais importantes de acesso à população adolescente e jovem, para que possam conhecer o que está presente na cultura corporal de movimento e reafirmar a importância desse componente curricular à vida.

No entanto, Darido (2004) já havia constatado que existia um desinteresse gradual dos estudantes pela EF, que iniciava nos anos finais do ensino fundamental e aumentava no decorrer do EM. Diante dessa preocupação, Bergmann e Lettnin (2011) investigaram a estrutura organizacional da EF em algumas escolas de EM em Porto Alegre e descobriram que as turmas, ainda, se encontravam organizadas por série/ano e separadas por gênero, evidenciando nenhum avanço nesse sentido.

Couto (2009) já havia afirmado que o sistema seriado, apesar das críticas, ainda, era a forma de organização do sistema educacional para a maioria das instituições escolares. Talvez, por ser a opção mais fácil para a organização, estruturação e o funcionamento das escolas, embora a literatura sobre o desenvolvimento humano já tenha apontado que os processos de aprendizagem ocorrem em tempos e ritmos diferentes, de acordo com as experiências dos alunos (GALLAHUE; OZMUN, 2005). Logo, a idade cronológica não deveria servir como parâmetro para a organização escolar.

Então, pensando nisso, Lettnin (2013) propõe que as turmas de EF no EM sejam organizadas por alunos de diferentes anos de ensino (1ํㅡㄹ $2^{\circ}$ e $\left.3^{\circ}\right)$, a partir de seus interesses sobre a cultura corporal de movimento prevista nos Parâmetros Curriculares Nacionais - PCN (BRASIL, 1997) e, 
atualmente, na Base Nacional Comum Curricular - BNCC (BRASIL, 2017). Nessa proposta o interesse do aluno na modalidade (práticas físico-esportivas), no nível de conhecimento (inicial, intermediário e avançado) e na afinidade social (colegas/amigos) são considerados para a composição das turmas.

A autora pretendia com a proposta de (Des)seriação amenizar os constrangimentos que surgiam, principalmente nesta etapa do ensino, devido à exposição em processos inadequados à capacidade dos alunos, muitas vezes sem sentido e significado para os mesmos. Com essa proposta, acreditava favorecer um ambiente agradável de aprendizagem para um estilo de vida cada vez mais saudável fisicamente, socialmente, psicologicamente e espiritualmente. Assim, as práticas físico-esportivas propostas pelos alunos na EF poderiam contemplar os diversos interesses com a integração dos diferentes anos de ensino $\left(1^{\circ}, 2^{\circ}, 3^{\circ}\right)$, ao considerarem suas afinidades sociais, muito importantes para adesão às práticas e a intensidade/nível de conhecimento das aulas, em que os objetivos poderiam ser propostos e desenvolvidos de forma desafiadora, tornando a aula mais atraente para todos.

A proposta para a EF elaborada por Lettnin (2013) foi implementada em 2012, numa escola da rede federal de ensino de Porto Alegre e perdura até hoje (2020). A cada início de semestre/trimestre é realizada uma assembleia geral com os alunos do EM para elencarem as modalidades de EF de seu interesse. Posterior a isso, é previsto um intervalo de tempo para os alunos pensarem e conversarem sobre as práticas físico-esportivas que poderão ocorrer naquele período. Em dia previamente marcado, os alunos elegem as modalidades por votação e se inscrevem nas turmas levando em consideração seus gostos, seus objetivos e suas relações interpessoais.

É importante ressaltar que, na opinião da autora, essa forma de estruturação das turmas só poderá ser implementada nas escolas se respeitar o pré-requisito básico relacionado ao ensino fundamental, no qual o aluno deverá entrar em contato com a cultura corporal de movimento indicada nos PCN (BRASIL, 1997) e, atualmente, na BNCC (BRASIL, 2017) durante os 9 anos de ensino. Assim, os alunos terão aprendido ou vivenciado, no ensino fundamental, inúmeras práticas relacionadas às unidades temáticas da EF (jogos, ginásticas, esportes, danças, lutas e práticas de aventura), lhes dando condições para realizar escolhas diversificadas no EM.

A autora acredita que a possibilidade de escolha por parte dos estudantes poderá fidelizá-los nas propostas pedagógicas da EF e estabelecer maior nível de MI, satisfazendo as três Necessidades Psicológicas Básicas (NPB) da Teoria da Autodeterminação (Self DeterminationTheory - SDT), proposta por Ryan e Deci (2000, 2007), pois os alunos terão autonomia para escolher sua modalidade, se sentirão competentes ao se submeterem a desafios adequados ao seu nível de 
conhecimento e pertencentes ao optarem por seus grupos sociais, seja por afinidade ou por objetivos comuns.

Segundo Ryan e Deci (2000, 2007), a satisfação das NPB regulará a motivação para formas mais autônomas, por meio das quais estão internalizadas as escolhas, interesses e desejos pessoais, sendo de extrema importância para a sua manutenção. Para Ryan e Deci (2000), Balbinotti e Capozzoli (2008), Balbinotti et al. (2011) e Silva et al. (2012) pessoas autonomamente motivadas demonstram maior persistência, empenho, esforço e prazer nas atividades que realizam.

Os resultados da investigação realizada por Lettnin (2013) foram satisfatórios em relação à frequência/permanência dos estudantes nas aulas de EF, mas durante os anos de 2014, 2015 e 2016 o projeto sofreu algumas alterações de ordem estrutural, sugeridas pela equipe de professores do EM (todas as áreas do conhecimento), que podem ter afetado a motivação dos alunos para as aulas desse componente curricular.

Explica-se que o projeto do EM desta escola conta com algumas disciplinas que fazem parte do currículo flexível, permitindo que estudantes percorram trajetórias distintas, baseada especialmente em seus interesses. Essas disciplinas de alguma forma contribuíram para que a organização (des)seriada na EF fosse possível. Para compor as turmas de EF, os alunos do EM foram divididos em duas faixas horárias. Enquanto metade dos estudantes estavam na EF, a outra metade estava dividida entre as Disciplinas Eletivas $(\mathrm{DE})^{1}$ e de Iniciação Científica (IC) ${ }^{2}$, que ocorriam no mesmo horário.

No ano de 2012, a EF foi organizada em quatro períodos de 1 h05min, divididos em duas faixas-horárias, ficando dois períodos por semana intercalados (terças e sextas-feiras) para cada metade do grupo de alunos do $\operatorname{EM}\left(1^{\circ}, 2^{\circ}\right.$ e $3^{\circ}$ anos misturados $)$ - 105 alunos em cada faixa-horária. O critério para determinar a quantidade de atividades físico-esportivas efetuadas por semestre/trimestre deveria considerar o número de alunos existentes no EM e o número de professores disponíveis. No primeiro ano de vigência do projeto, foram oferecidas 05 modalidades em cada faixa-horária, totalizando 10 modalidades oferecidas por semestre.

Em dia previamente determinado, após promover um tempo para os alunos $(\mathrm{n}=210)$ compartilharem suas ideias, eles, independentemente do ano, fizeram a escolha das modalidades em uma ficha, juntamente com o horário (por faixa-horaria) das propostas de Iniciação Científica (IC) e Disciplinas Eletivas (DE) do projeto do EM. Na EF aquelas modalidades com maior número de

\footnotetext{
${ }^{1}$ As Disciplinas Eletivas fazem parte do currículo flexível do projeto de EM da escola pesquisada e são propostas diferenciadas, com número de vagas limitados, que levam em consideração a escolha dos alunos.

${ }^{2}$ A Iniciação Científica são projetos de pesquisa e/ou de aprendizagem desenvolvidos a partir do interesse dos estudantes. As temáticas sugeridas pelos alunos são aproximadas pelos professores orientadores para constituir os grupos. Essa disciplina também faz parte do currículo flexível do projeto de EM dessa escola.
} 
alunos inscritos foram ofertadas. As modalidades que apresentaram o número de alunos superior ao número de vagas tiveram sorteio, sendo os alunos não contemplados redistribuídos para a sua segunda ou terceira opção. Da mesma forma, foram reconduzidos aqueles alunos que optaram por modalidades pouco votadas.

Em 2013 ocorreram duas mudanças importantes: 1) os alunos realizaram a escolha da modalidade físico-esportiva anteriormente as propostas de IC e DE serem divulgadas; 2) aumentou o número de ofertas das modalidades físico-esportivas, de 5 para 6 em cada faixa-horária, devido ao aumento do número de alunos no EM, que passou de 210 para 235 alunos.

Em 2014 houve apenas uma mudança: os alunos escolheram a modalidade de EF em regime semestral, concomitante as propostas de IC e DE em regime anual. As propostas anuais de IC e DE engessaram o grupo de alunos em cada faixa-horária, impedindo que eles transitassem, no segundo semestre, pelas práticas físico-esportivas da outra faixa-horária. Isso prejudicou a diversidade de modalidades ofertadas e, consequentemente, pode ter dificultado a satisfação dos interesses dos estudantes.

Em 2015, os alunos escolheram primeiro as disciplinas de IC e DE em regime anual, para depois elegerem as modalidades de EF em cada trimestre. Com isso, os grupos já foram previamente formados para a EF em cada faixa-horária durante o ano. No mesmo sentido, esse formato dificultou a variação das práticas físico-esportivas, pois separou os alunos que tinham interesse na mesma modalidade. Isso pode ter desqualificado a prática e, por outras vezes, inviabilizado a realização de novas modalidades pelo número insuficiente de alunos, prevalecendo as modalidades mais tradicionais que são, geralmente, as mais votadas.

Em 2016, quatro mudanças importantes foram implementadas: 1) a desvinculação da EF e as disciplinas IC e DE, ocorrendo em períodos diferentes na grade horária do EM; 2) a duração dos períodos de 1 h05min, para um período de $1 \mathrm{~h} 30$ min e o outro de 45 minutos; 3 ) a divisão do grupo em turmas pares e ímpares, ficando quatro turmas (101, 201, 301 e 303), em uma faixa-horária, para compor o grupo das turmas ímpares e três turmas $(102,202,302)$, em outra faixa-horária, para compor o grupo das turmas pares; 4) a separação das turmas de terceiro ano do restante do EM para a escolha das disciplinas de IC e DE.

Ao conhecer os critérios adotados em cada ano, que balizaram o processo de escolha para composição das turmas de EF na escola investigada, destaca-se que a questão central desse estudo traz a preocupação acerca do comportamento motivado ou desmotivado dos estudantes do EM e suas consequências, frente aos procedimentos diferenciados para as escolhas das modalidades. Nesse sentido, é fundamental compreender se essas alterações trouxeram mudança significativa no nível de motivação dos estudantes entre os anos investigados. 


\section{PROCEDIMENTOS METODOLÓGICOS}

Esta investigação se caracterizou por um estudo descritivo exploratório, do tipo misto (quantitativo e qualitativo). As pesquisas mistas de acordo com Creswell e Plano Clark (2013) são recomendadas com o propósito de melhorar o conhecimento a respeito do processo em estudo. Conforme Pais-Ribeiro (2009), o estudo quantitativo objetiva a generalização dos resultados, expresso por meio de números, que podem corresponder a construtos ou teorias para os pesquisadores. Enquanto que o estudo qualitativo, segundo Minayo (2001), não pode ser reduzido à operacionalização de variáveis, pois analisa de forma profunda um universo de significados, motivos, aspirações, crenças, valores e atitudes ligadas as relações, processos e/ou fenômenos.

Vale ressaltar que essa pesquisa cumpriu com os procedimentos éticos e legais e que faz parte de um projeto de investigação amplo que estuda a (Des)seriação da EF, aprovado na Plataforma Brasil - parecer número 184.410. Além disso, os participantes e/ou responsáveisreceberam o Termo de Consentimento Livre e Esclarecido e as explicações sobre os objetivos da pesquisa e orientações sobre os procedimentos a serem realizados na coleta de dados.

Para a coleta das informações do estudo quantitativo, utilizou-se o questionário denominado por Lettnin (2013) Bem-Estar Discente na EF (BEDEF). Para este estudo, considerou-se apenas as questões sobre o gosto pela EF epela (Des)seriação e as respostas relativas as escalas de MI edas NPB em EF (NPB_EF). Já para o estudo qualitativo,utilizou-se o conteúdo descrito na questão aberta, que foi incluída na coleta do ano 2016, na qual permitia aos alunos descreverem a percepção deles sobre pontos positivos e/ou negativos na EF (des)seriada do EM.

Explica-se que a escala de MI foi adaptada ao contexto da EF por Lettnin (2013) e possui 4 itens que são avaliados em 7 pontos (1 - Discordo totalmente; 2 - Discordo bastante; 3 - Discordo um pouco; 4 - Não discordo, nem concordo; 5 - Concordo moderadamente; 6 - Concordo bastante ; 7 - Concordo totalmente). E a escala de NPB_EF, adaptada por Lettnin et al. (2013), compreende 3 dimensões da SDT de Ryan e Deci (2000, 2007): Autonomia (3; 6; 9; 12); Competência (1; 4; 7; 10) e Pertencimento $(2 ; 5 ; 8 ; 11)$, possuindo 12 itens que são avaliados em 5 pontos ( 1 - Discordo totalmente; 2 - Discordo; 3 - Não concordo, nem discordo; 4 - Concordo; 5 - Concordo totalmente).O resultado das escalas é composto pela soma dos itens, sendo que a escala de MI poderá atingir o escore bruto de no mínimo 04 e no máximo 28 pontos e a escala de NPB_EF poderá ter um escore geral bruto de 12 a 60 pontos ou por dimensão de 4 a 20 pontos. 
Em dia previamente marcado, o instrumento foi respondido pelos estudantes que aceitaram participar do estudo, em ambiente coletivo, sob supervisão dos pesquisadores, durante uma das aulas indicadas pelo grupo de professores do EM.Ressalta-se que foi assegurada a participação voluntária na pesquisa, além do anonimato e confidencialidade das informações coletadas.Para garantir o anonimato dos participantes, o instrumento foi codificado. Dessa forma, cada estudante recebeu a letra "E" e um número, como por exemplo E9.Participaram deste estudo estudantes do EM de uma escola da rede federal de ensino do Rio Grande do Sul, sendo em 2012 (n=160), em $2014(\mathrm{n}=184)$, em 2015 (n=180) e em 2016 (n=169). É importante dizer que o público alvo desta escola se caracteriza pela diversidade sócio-cultural-econômica devido ao meio de acesso democrático por sorteio.

Após a coleta de dados, as respostas das escalas foram inseridas no programa estatístico SPSS 18.0 forwindows. Utilizou-se para análise dos dados quantitativos estatística descritiva e de comparação entre grupos, por meio do teste de Tukey. Já para os dados qualitativos, utilizou-se Análise de Conteúdo segundo Moraes (1998) e seu corpus foi composto pelas respostas dos alunos sobre a questão aberta (Faça uma avaliação com pontos positivos e/ou negativos da EF atual). Essa análise, conforme o autor, pressupõem cinco etapas denominadas: 1. preparação das informações; 2. desconstrução e unitarização; 3. categorização; 4. descrição e 5. interpretação. Neste estudo as unidades de análise foram definidas por categorias emergentes identificadas nas respostas dos alunos.

\section{A MOTIVAÇÃo DISCENTE NA EF (DES)SERIADA: ANÁLISE QUANTITATIVA}

Para iniciar esta parte do estudo, optou-se por apresentar, primeiramente, a análise que identifica o gosto dos alunos quanto a EF e a proposta (des)seriada, para posteriormente descrever as variáveis motivação intrínseca (MI) e as NPB_EF (autonomia, competência e pertencimento) da SDT em cada ano investigado, observando as alterações adotadas para compor as turmas (des)seriadas à EF.

Ao identificar o gosto dos alunos quanto à EF e à estrutura organizacional (des)seriada, constatou-se que dos 529 questionários respondidos sobre a EF, 87,7\% $(n=464)$ de respostas positivas apontam que os alunos do EM gostam desse componente curricular, e, que dos 523 questionários preenchidos a respeito da (Des)seriação, 84,1\% $(\mathrm{n}=440)$ indicam respostas favoráveis à proposta. Esse resultado positivo com relação ao gosto dos alunos pela EF escolar corrobora com 
os resultados encontrados nos estudos realizados por Darido (2004); Brandolin, Koslinski e Soares (2015) e Einsfeldt e Lettnin (2018), que apontaram satisfação dos estudantes por esse componente curricular. Além disso, o resultado que revela o gosto pela proposta (des)seriada demonstra o quanto a maioria dos estudantes aprovam essa nova estrutura de organização das turmas, já constatado no estudo de Lettnin (2013), revelando-se um caminho para novas organizações escolares.

Dando continuidade aos objetivos da pesquisa, de analisar a média dos escores das variáveis MI, Autonomia, Competência e Pertencimento, e, poder compará-las durante os anos de implementação da proposta, foram elaborados gráficos que compõem a Figura 1 a seguir, para melhor compreensão dos resultados descritos.

Conforme os gráficos 1, 2, 3 e 4 (representados na Figura 1), de forma geral, é possível identificar pelos resultados que os alunos do EM apresentaram médias de escores mais elevadas nas variáveis pesquisadas em 2014 e 2015, e que em 2016, as médias das variáveis diminuíram, com exceção da variável pertencimento. Observa-se ainda que no ano de implementação da proposta (des)seriada, em 2012, às médias das variáveis pesquisadas foram menores em relação aos demais anos coletados. E que é possível perceber leve ascensão das variáveis competência (gráfico 2) e autonomia (gráfico 4) da implementação até 2015, ou seja, na medida em que os anos foram passando o nível dessas variáveis foram aumentando ou sendo reforçados. 
Figura 1 - Comparação das média das variáveis MI, Pertencimento, Competência e Autonomia

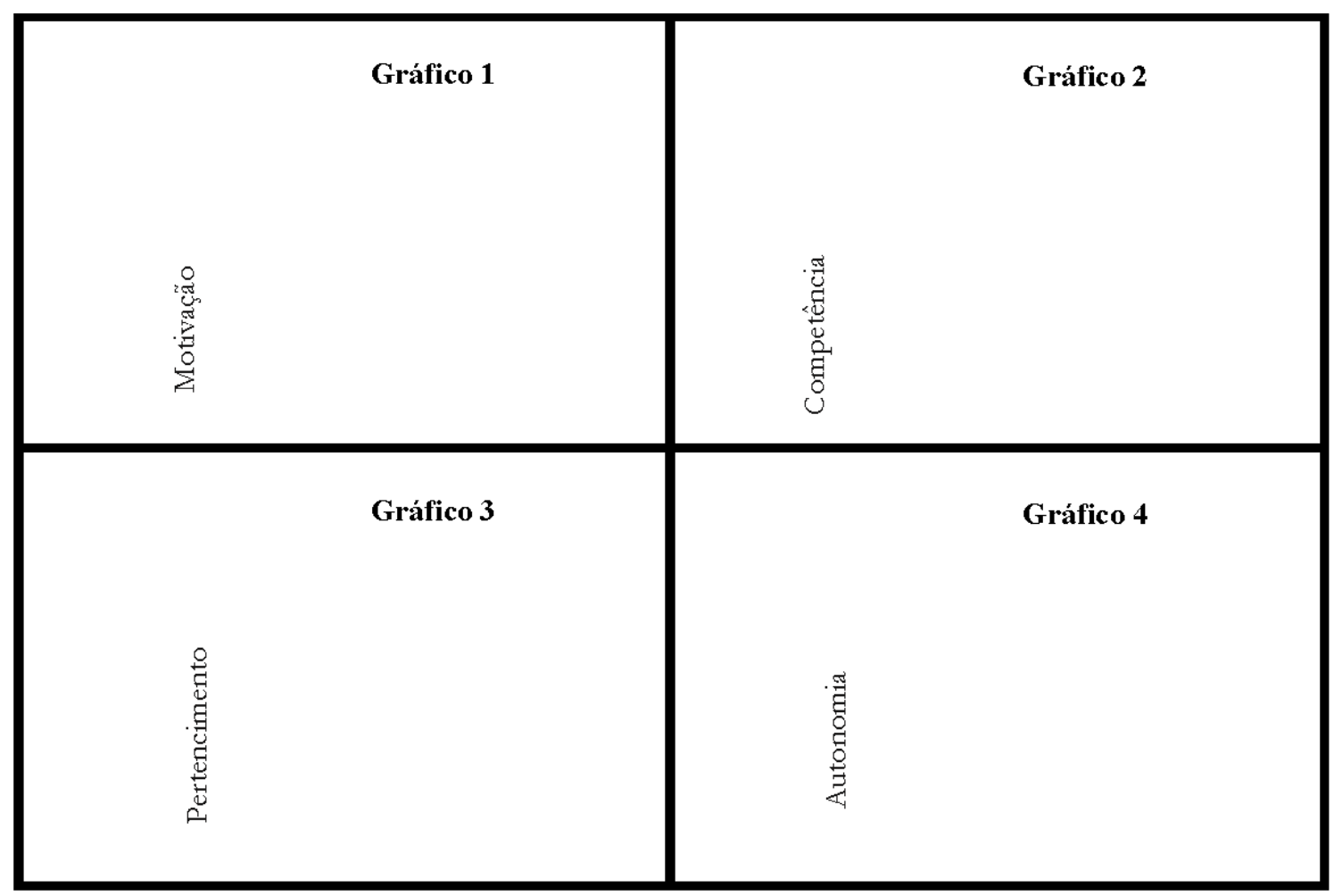

Fonte: Elaborada pelos autores.

Pode-se pensar que as médias superiores nesses anos de 2014 e 2015 são reflexo da familiarização dos estudantes com a proposta (des)seriada, pois na implementação, em 2012, os alunos a desconheciam e foram consultados a respeito dela após terem experimentado, apenas, 4 meses de aulas nessa nova estrutura de organização das turmas. No decorrer do processo, mesmo com as modificações adotadas em 2014 e 2015 que reduziram o trânsito dos alunos nas modalidades, durante os semestres/trimestres, ainda era possível consultá-los sobre "o que" e "com quem" gostariam de fazer aula. Assim, os resultados positivos podem ter sido reforçados pela segurança e conhecimento das possibilidades que a proposta proporcionava, refletindo em melhora da satisfação em relação às variáveis investigadas, pois os alunos ao escolherem (autonomia) o que fazer, poderiam satisfazer seus interesses, e, com quem fazer, poderiam determinar o nível daquela prática, dentro de um ambiente adequado as suas possibilidades (competência), conforme intencionou Lettnin (2013).

Por outro lado, nos gráficos da Figura 1, é possível observar a sensível queda da MI que inicia em 2015 e a redução das médias das demais variáveis em 2016 (com exceção do pertencimento), revelando que as alterações, realizadas em 2015 e 2016, podem ter contribuído com esses resultados mais baixos nas variáveis investigadas, na medida em que os estudantes tiveram suas possibilidades e opções reduzidas gradativamente. Essa queda brusca em 2016, por exemplo, 
pode ser justificada pela separação das turmas pares e ímpares. Essa norma impediu o encontro de determinados alunos e pode ter desqualificado a prática ou dificultado a realização de determinada modalidade. Entende-se que há perda de qualidade quando alunos, com os mesmos interesses, são impedidos de se encontrar ou forçados a optarem por práticas que não correspondem às suas expectativas. Outra questão é a dificuldade de oferta de algumas modalidades pela falta de quórum. Nesse sentido, a divisão em turmas pares e ímpares pode ter influenciado a autopercepção dos estudantes, os quais se perceberam menos autônomos e competentes em 2016.

$\mathrm{Na}$ análise do gráfico 1 é evidente o crescimento da variável MI no ano de $2014(\mathrm{M}=4,90)$ em relação ao ano de $2012(\mathrm{M}=4,54)$, o que corrobora com a aceitação da proposta indicada no estudo de Lettnin (2013). Já nos gráficos 2 e 3 da Figura 1 observa-se que a autopercepção dos discentes sobre sua competência e sua autonomia é melhor no ano de $2015(\mathrm{M}=4,05$ e $\mathrm{M}=3,75$, respectivamente), seguida da avaliação realizada pelos alunos no ano de 2014 ( $M=4,00$ e $M=3,64$, respectivamente). Ao analisar o pertencimento (gráfico 3) dos alunos, pode-se constatar que a avaliação mais positiva ocorreu no ano de $2014(\mathrm{M}=4,05)$, depois em $2016(\mathrm{M}=4,00)$ e em 2015 $(\mathrm{M}=3,97)$, diferenciando-se dos demais fatores. A pequena diferença entre as médias dos anos investigados dessa variável revelou que as alterações, para a organização das turmas de EF, parecem não influenciar o pertencimento dos estudantes, demonstrando que as relações sociais permanecem após serem constituídas, independentemente da convivência diária nas aulas de EF ou outros espaços do ambiente escolar.

Conforme a pesquisa de Lettnin (2013), mais de 60\% dos alunos diversificaram suas modalidades na EF (des)seriada durante o ano 2012, ampliando a convivência na escola. Esse comportamento pode ter permanecido ao longo dos anos, favorecendo o convívio dos estudantes em diferentes grupos (des)seriados, fortalecendo assim as relações sociais.

No sentido de compreender esses resultados e cumprir com o objetivo da pesquisa de verificar a motivação dos estudantes, frente às alterações para composição das turmas de EF, serão descritas a seguir as comparações das médias das variáveis de cada ano, no sentido de averiguar, por meio do teste de Tukey, se as diferenças apresentadas são significativas.

Os resultados do teste apontaram que as diferenças encontradas na variável MI, entre os anos do estudo, não são estatisticamente significativas. Isso quer dizer que as alterações (fatores externos) realizadas para a composição das turmas de EF, não modificou aquilo que é próprio de cada estudante (fatores internos), caracterizando-se como uma variável de cunho pessoal.

Diferentemente das variáveis competência e autonomia que apresentaram diferenças estatisticamente significativas, respectivamente $p=0,017$ e $p=0,007$, apenas, entre as médias dos anos $2012(\mathrm{M}$ comp=3,82; $\mathrm{M}$ aut=3,45) e $2015(\mathrm{M}$ comp=4,05; $\mathrm{M}$ aut=3,75). Esse resultado vem 
corroborar com o que foi anteriormente exposto, pois a autopercepção dos estudantes sobre autonomia e competência melhorou com o passar dos anos, independentemente dos critérios externos estabelecidos em 2015 para a composição das turmas (des)seriadas de EF.

Já a variável pertencimento, diferente das outras variáveis, apresentou diferenças estatisticamente significativas entre as médias obtidas em todos os anos investigados (2014, 2015 e 2016), quando comparados com a média do ano 2012. A maior diferença obtida $(p=0,002)$ foi entre o ano $2012(\mathrm{M}=3,74)$ e o ano $2014(\mathrm{M}=4,05)$, em que os alunos tinham maior liberdade e escolheram primeiro as modalidades da EF, seguido do ano $2016(\mathrm{M}=4,00 ; \mathrm{p}=0,024)$ em que os alunos foram divididos em turmas pares e impares e $2015(\mathrm{M}=3,97 ; \mathrm{p}=0,040)$ em que os alunos foram engessados em uma única faixa-horária. Destaca-se que essa variável apresentou estabilidade positiva após a implementação, independentemente das alterações adotadas para compor as turmas de EF no EM. Esse fato pode ser uma característica dessa variável que alcançou média elevada em 2014 e manteve seus parâmetros nos demais anos, justificando um dos objetivos prioritários da proposta com relação a saúde social dos estudantes. Conforme Lettnin (2013), a proposta da (Des)seriação foi criada para reforçar e ampliar as relações interpessoais ao longo dos anos, o que poderá facilitar e promover o sentimento de pertencer.

Com o intuito de qualificar e complementar a discussão até aqui exposta a cerca das alterações das médias das variáveis investigadas, apresentar-se-á, a seguir, a análise qualitativa sobre a visão discente, buscando conhecer e compreender algumas questões implicadas nesse processo, que podem explicar a variação dos resultados sobre a motivação.

\section{PONTOS POSITIVOS E NEGATIVOS SOBRE A EF (DES)SERIADA: VISÃO DISCENTE}

Essa análise foi originada dos resultados extraídos da questão aberta, incluída no instrumento BEDEF em 2016. Nessa questão, os alunos apontaram os pontos positivos e negativos da proposta de EF (des)seriada, expressando suas opiniões de forma crítica a respeito de suas experiências nas aulas. Com o objetivo de reconhecer a visão dos discentes sobre a proposta de EF (des)seriada, as respostas foram tratadas por análise de conteúdo, conforme Moraes (1998), como já descrito nos procedimentos metodológicos.

Vale ressaltar que nos achados da questão qualitativa os alunos indicaram ter preferência pelos sistemas (des)seriados anteriores a 2016, em que ocorreram maior nível de MI por parte dos estudantes, conforme revelou o estudo quantitativo. Os alunos, também, assumiram em seus 
escritos, que há descontentamento com as normas estabelecidas em 2016 (turmas pares e impares) para a composição das turmas e escolha das modalidades, ano em que os índices declinaram na maioria das variáveis, conforme os gráficos representados na Figura 1.

Em resumo, os alunos reportaram que: anteriormente, as escolhas de DE, IC e EF eram realizadas por eles (manutenção da autonomia) e os grupos eram constituídos por todas às 07 turmas do EM (as escolhas ainda eram avaliadas pelos estudantes dentro de um processo de perdas e ganhos). Já em 2016, o critério de separação das turmas pares e ímpares, para a constituição dos grupos de EF, feriu o protagonismo dos alunos (que estavam acostumados a transitar entre todas as turmas do EM e fazer suas escolhas), pois foi pré-determinado pelo grupo de professores desse nível de ensino, sem uma consulta aos envolvidos ou uma avaliação de suas consequências ou limitações. Para melhor compreender as críticas emitidas pelos alunos, descreve-se a seguir a análise de conteúdo, apresentando as categorias do estudo (Tabela 1) que foram definidas a posteriori, levando em consideração sua frequência.

Tabela 1 - Pontos positivos $(\mathrm{n}=167)$ e negativos $(\mathrm{n}=201)$ da proposta (des)seriada

\begin{tabular}{|c|c|c|c|c|c|}
\hline \multirow[t]{2}{*}{ Categorias } & \multirow[t]{2}{*}{ Subcategoria } & \multicolumn{2}{|c|}{$\begin{array}{c}\text { Visão } \\
\text { positiva } \\
(45,4 \%) \\
\end{array}$} & \multicolumn{2}{|c|}{$\begin{array}{c}\text { Visão } \\
\text { Negativa } \\
(\mathbf{5 4 , 6 \% )} \\
\end{array}$} \\
\hline & & $\mathbf{F}$ & $\%$ & $\mathbf{F}$ & $\%$ \\
\hline $\begin{array}{c}\text { Aspectos } \\
\text { estruturais do } \\
\text { projeto }\end{array}$ & $\begin{array}{c}\text { Constituição das turmas; } \\
\text { Tempo de aula; } \\
\text { Oferta de modalidades; } \\
\text { Horário; } \\
\text { No } \text { de alunos; } \\
\text { Espaço físico/infraestrutura }\end{array}$ & 102 & 61,07 & 129 & 64,18 \\
\hline $\begin{array}{l}\text { Aspectos da teoria } \\
\text { da } \\
\text { autodeterminação }\end{array}$ & $\begin{array}{c}\text { Autonomia; } \\
\text { Pertencimento; } \\
\text { Competência }\end{array}$ & 34 & 20,36 & 37 & 18,41 \\
\hline Aspectos da saúde & $\begin{array}{c}\text { Social; } \\
\text { Psicológicos; } \\
\text { Espiritual; } \\
\text { Físico; } \\
\text { Saúde geral } \\
\end{array}$ & 25 & 14,97 & 27 & 13,43 \\
\hline Aspectos pessoais & $\begin{array}{c}\text { Individualidades; } \\
\text { Características; } \\
\text { Gostos } \\
\end{array}$ & 06 & 3,59 & 03 & 1,49 \\
\hline $\begin{array}{c}\text { Aspectos } \\
\text { pedagógicos }\end{array}$ & $\begin{array}{l}\text { Prioridade à estudantes mais } \\
\text { habilidosos; } \\
\text { Metodologia do professor; } \\
\text { Cobrança professor-aluno }\end{array}$ & - & - & 05 & 2,49 \\
\hline
\end{tabular}

Fonte: Elaborado pelos autores. 
Conforme a Tabela 1, foram encontradas 368 respostas sobre a avaliação discente da EF (des)seriada no EM, sendo 45,4\% ( $\mathrm{n}=167)$, representando pontos positivos e 54,6\% ( $\mathrm{n}=201)$, representando pontos negativos. As categorias identificadas tanto para retratar os pontos positivos quanto os negativos foram: Aspectos estruturais do projeto, Aspectos da teoria da autodeterminação, Aspectos da saúde e Aspectos pessoais. Os Aspectos pedagógicos surgiram apenas para denunciar pontos negativos à proposta. Pode-se observar também na Tabela 1, que as 03 primeiras categorias permaneceram na mesma ordem de importância tanto para retratar os pontos positivos como negativos, sendo, Aspectos estruturais do projeto a categoria que demanda maior atenção na visão dos estudantes.

A categoria Aspectos estruturais do projeto é caracterizada pela forma de constituição dos grupos na EF; o tempo de aula; a oferta das modalidades; o horário das aulas; a infraestrutura e o $\mathrm{n}^{\circ}$ de alunos. Na visão positiva, a categoria é retratada por E1173, estudante do primeiro ano do EM, ao relatar suas experiências anteriores:

Acho muito bom as turmas do ensino médio juntas [...]. Sou velho no colégio, é a primeira vez que pude ver as turmas juntas(E1173).

O relato de E1173 demonstra que a proposta de (Des)seriação é inovadora e favorável aos estudantes do EM, conforme já destacaram os estudos de Bergmann e Lettnin (2011), Lettnin, (2012; 2013); Lettnin, Jesus e Stöbaus (2012); Einsfeldt e Lettnin (2018).

$\mathrm{Na}$ visão negativa a categoria Aspectos estruturais do projeto é caracterizada por E1075 e E1021 ao revelarem:

Acho um aspecto negativo divisão pares e ímpares porque reprime a socialização entre os alunos, privando as relações em apenas um grupo, tornando óbvio que o convívio dos alunos será repetitivo [...] (E1075).

Esse ano eu queria fazer uma modalidade, mas nunca foi elegida, porque não possui número suficiente de gurias (E1021).

A fala dos estudantes deixa claro que as novas diretrizes para a formação das turmas de EF, em 2016, privam sua liberdade de escolha, refletindo de forma negativa nas relações interpessoais e no atendimento de seus interesses. Autores que estudam a satisfação das NPB reforçam a importância de preservar a autonomia para obter comportamentos mais autodeterminados e alcançar níveis elevados de MI. Assim, acreditam aumentar a persistência, o esforço, o envolvimento e o 
prazer nas atividades físicas (RYAN; DECI, 2000, 2007; BALBINOTTI; CAPOZZOLI, 2008; BALBINOTTI et al., 2011 e SILVA et al., 2012).

A categoria Aspectos da teoria da autodeterminação retrata questões ligadas à autonomia, competência e pertencimento que são os fatores que sustentam essa teoria. Sobre ela em uma visão positiva destaca-se a manifestação do estudante E1173:

Gosto muito da parte de escolher a modalidade, pois não vou pela força dos professores e sim por algo que gosto ou me sinto mais a vontade [...](E1173).

Para o estudante E1173, a autonomia garantida na proposta de (Des)seriação atende aspectos pessoais e direciona o aluno para ambientes mais adequados e seguros, conforme intencionou Lettnin (2013). Também, conforme Ryan e Deci (2000) é fundamental para o engajamento dos alunos nas aulas de EF que as questões internas (escolhas, desejos, interesses) sejam correspondidas a fim de satisfazer as NPB que promoverão a motivação. Por isso, gostos e interesses de cada aluno devem ser reconhecidos e considerados no processo de escolha de cada prática físico-esportiva, para favorecer os ambientes de aprendizagens.

No momento em que as regras mudaram e engessaram a escolha dos alunos nas faixa-horárias (turmas pares e impares), restringiu-se a autonomia dos alunos e a mesma categoria (Aspectos da teoria da autodeterminação) passa ser representada por uma visão negativa, conforme o estudante E1189 quando diz que:

Antes eu poderia escolher meus horários (as faixas horárias), as disciplinas, escolher a eletiva e a educação física [...] nos dá liberdade de escolher os horários de acordo com a minha vontade/disponibilidade, me da liberdade de escolher com quem eu quero fazer aulas [...](E1189).

Foi para isso que a proposta de (Des)seriação na EF foi elaborada, pautada pelo protagonismo dos estudantes. A intenção de permitir o trânsito dos alunos para que suas escolhas atendessem suas peculiaridades e interesses, objetivava facilitar os processos de ensino e de aprendizagem (LETTNIN, 2013).

De acordo com Berleze, Vieira e Krebs (2002), quando uma pessoa está motivada e dá a devida importância para aquilo que está realizando, aumentam as chances de compreensão, aprendizagem e desempenho.

Outro elemento negativo relacionado à categoria Aspectos da teoria da autodeterminação, reportado pelos estudantes, diz respeito à competência do professor, ao exigir conhecimento da 
modalidade, e a competência do aluno, que ficou prejudicada com a divisão das turmas pares e impares:

Colocar professores com mais 'experiência' em tal esportes. Por exemplo, professores que já tenham trabalhado mais tempo com o futebol, [...] (E1147).

Não nivelamento dos alunos resultando em aulas, por vezes, muito iniciantes (E1026).

Estudos apontam que é fundamental o aluno se sentir competente tanto para enfrentar os desafios propostos quanto para realizar as tarefas em aula. Despertar esse sentimento de competência nos estudantes é necessário para ele permanecer por mais tempo engajado nas atividades (MOUTÃO; ALVES; CID, 2012; EINSFELDT; LETTNIN, 2018).

Outra categoria presente nas respostas dos estudantes foi Aspectos da Saúde, sendo a terceira categoria que mais se manifestou. É compreendido dentro desta categoria aspectos ligados à saúde geral; ao psicológico; ao espiritual; ao físico e ao social. Para revelar aspectos positivos à proposta em relação aos Aspectos da Saúde, os estudantes descreveram:

Me sinto muito bem ao fazer a educação física, qualquer problema que ocupe a minha mente é desfeito e começo a me dedicar ao máximo no tempo que tenho(E1028).

A (Des)seriação [...] auxilia a nossa vida social, nos ajuda a fazer novos amigos e nos ensina a confraternizar (E1145).

Já para apontar aspectos negativos os estudantes afirmaram que:

Fazer educação física agora (2016) é muito ruim e massante, pois é ofertado sempre as mesmas opções [...] (E1082).

A ideia de colocar as turmas divididas em pares e ímpares não foi legal, pois queremos fazer as aulas com amigos/colegas também [...] (E1055).

Na perspectiva de Lettnin (2013), o projeto de (Des)seriação na EF do EM foi criado, com base nas NPB da SDT, para contribuir com a saúde dos estudantes ao criar um ambiente favorável à aprendizagem acerca das manifestações da cultura corporal de movimento. Os resultados da categoria Aspectos da Saúde demonstram o potencial da proposta em cumprir com esse objetivo, desde que seja preservado o protagonismo do estudante no processo.

A categoria Aspectos pessoais tratou dos pontos mais particulares de cada aluno, ressaltando seus gostos e suas individualidades. Reforçando os aspectos positivos, para o estudante E1169 a EF 
atende o seu interesse, e, para retratar a visão negativa o estudante E1003 descreve que na sua opinião a EF deveria ser opcional:

Eu gosto do que faço na educação física [...] (E1169).

Não gosto que a educação física seja obrigatória [...] (E1003).

Os aspectos pessoais são características que individualizam os estudantes e tornam os processos educativos ainda mais complexos. Atender essas individualidades, em turmas extremamente heterogêneas, nem sempre é tarefa fácil. Conforme Silva et. al. (2007), a desmotivação é um processo dinâmico e multifatorial, que se refere a razões pessoais, conscientes e inconscientes.

Por fim, a categoria Aspectos pedagógico apareceu nas respostas dos alunos apenas sob o ponto de vista negativo. Essa categoria está representada pelas escolhas, formas e estilos metodológicos dos professores. O relato do estudante E1056 traz o descontentamento dele com a metodologia adotada por algum professor:

Não gosto de professores que priorizam quem joga bem (E1056).

Segundo Fonseca e Machado (2015), a aula deve ser um direito de todos e para isso é fundamental reconhecer que as diferenças existem e compreender as características individuais de cada um. Os autores, ainda, reconhecem que o preconceito que se instala diante de alunos menos habilidosos para as práticas esportivas no interior das aulas de EF é recorrente e defendem o debate sobre a questão das diferenças para enfrentar a situação, pois, em geral, os alunos excluídos são os que não respondem bem aos desafios propostos nas aulas.

Diante dos resultados quantitativos e qualitativos apresentados, pode-se aventar que as alterações realizadas para compor os grupos para EF no ano 2016, por turmas pares e ímpares, podem ter contribuído com o declínio das variáveis estudadas e estar associada as manifestações de descontentamento discente com a EF neste mesmo ano. Dessa forma, os estudantes se sentiram menos MI, autônomos e competentes e a percepção negativa sobre a EF foi maior em 2016, principalmente, na categoria Aspectos estruturais da proposta que envolveu, especialmente, a composição das turmas e a oferta das modalidades.

A separação das turmas pares e ímpares parece romper com o protagonismo e a autonomia que os estudantes tinham nos anos anteriores, uma vez que a oferta das modalidades e, consequentemente, as escolhas, são reduzidas nesse universo segmentado. $\mathrm{O}$ trânsito dos alunos 
com essa fragmentação fica limitado o que pode estar associado a percepções mais baixas da MI, da autonomia e da competência em 2016, pois os estudantes não fazem o que desejam e muitas vezes encontram-se em ambientes inadequados aos seus interesses e capacidades.

A manutenção do resultado da variável, pertencimento em 2016. pode ter explicação pautada no trabalho desenvolvido pela (Des)seriação em anos anteriores (2012 a 2015), em que os alunos ampliaram suas relações interpessoais demonstrando durabilidade dos relacionamentos sociais ao longo do tempo.

No estudo de Leitão et. al. (2011), as relações interpessoais são fundamentais para os alunos se sentirem dispostos a aprender. Para eles, os alunos em situação de aprendizagem nas aulas de EF vão depender, além de suas capacidades intelectuais/cognitivas e motoras, da capacidade de pedir, dar e receber ajuda. Acredita-se que ao promover essas interações nas situações de ensino e de aprendizagem, as relações interpessoais construídas são efetivadas e poderão ser aprofundadas e permanecer por longo período.

\section{CONSIDERAÇÕES FINAIS}

Com base na análise efetuada, os resultados demonstraram que as alterações estruturais efetuadas em 2016, para compor os grupos da EF no EM (separação da EF das disciplinas IC e DE; tempo dos períodos, divisão do grupo em turmas pares e ímpares; desvinculação das turmas do terceiro ano), trouxeram insatisfações aos estudantes, constatado tanto no declínio das médias da maioria das variáveis investigadas (motivação, autonomia, competência), como nos apontamentos dos discursos emitidos.

As demais mudanças ocorridas nos anos anteriores (2014 e 2015) mantiveram as médias das variáveis em estado crescente, desde a implementação da proposta (des)seriada em 2012. Esses resultados podem ser verificados tanto na análise quantitativa quanto na qualitativa, ao destacar preferências dos estudantes em relação aos sistemas anteriores a 2016. Acredita-se que as mudanças adotadas pelos professores do EM para compor os grupos de EF durante esses anos (2014 e 2015), preservaram, de certa forma, a autonomia e a participação dos estudantes em decidir suas trajetórias formativas.

Esse fenômeno de ascensão das médias das variáveis estudadas (2014 e 2015), desde a implementação (2012), parece estar ligado ao tempo de execução da proposta e ao livre arbítrio dos alunos, ou seja, quanto mais tempo os alunos experimentam a proposta, mais conheceram sobre suas possibilidades, fazendo com que suas escolhas fossem mais conscientes e seguras. Assim a 
preservação da autonomia dos alunos com maior liberdade de escolhas nos anos de 2014 e 2015 satisfizeram as demais NPB (competência e pertencimento), lhes trazendo maior nível de MI.

A variável pertencimento, que manteve seu resultado em 2016, necessita ser mais estudada, pois demonstrou ser uma variável estável, ou seja, as relações interpessoais ou o sentimento de pertencer uma vez conquistados não sofreram alterações imediatas com as modificações de composição das turmas.

Os resultados qualitativos reforçaram a necessidade de propostas que garantam aos estudantes percorrerem trajetórias distintas, afim de sanar suas necessidades e desejos no ambiente da EF escolar, ou seja, quanto mais opções o estudante tiver nas aulas de EF, maior serão as possibilidades de inclusão, participação e realização nesse contexto, garantindo engajamento efetivo dos estudantes e aprendizagem.

Reconhece-se as limitações do estudo sobre os diferentes níveis de autopercepção das variáveis estudadas por estudantes de sexo e faixas etárias variadas e sugere-se além de investigar essas limitações, que em estudos futuros sejam feitas análises acerca de processos de ensino e de aprendizagem da proposta (des)seriada, trazendo um enfoque maior na discussão sobre a progressão do ensino das práticas corporais em classes (des)seriadas, bem como, as escolhas de modalidades e sua influência no processo de aprendizagem dos alunos.

\section{REFERÊNCIAS}

BALBINOTTI, Marcos Alencar; CAPOZZOLI, Carla Josefa. Motivação à prática regular de atividade física: um estudo exploratório com praticantes em academias de ginástica. Revista Brasileira de Educação Física e Esporte, v. 22, n.1, p. 63-80, 2008. Disponível em: http://www.revistas.usp.br/rbefe/article/view/16683. Acesso em: 19 de out. de 2016.

BALBINOTTI, Marcos Alencar; BARBOSA, Marcus Levi; BALBINOTTI, Carlos Adelar; SALDANHA, Ricardo. Motivação à prática regular de atividade física: um estudo exploratório.Estudos de Psicologia (Natal), v. 16, n. 1, p. 99-106, 2011. Disponível em:https://www.scielo.br/scielo.php?script=sci arttext\&pid=S1413-294X2011000100013\&lng=pt\&tlng=pt. Acesso em: 05 de nov. de 2016.

BERGMANN, Laura; LETTNIN, Carla. Panorama da Educação Física escolar de Porto Alegre no ensino médio: estrutura e funcionamento. Cadernos do Aplicação/UFRGS, v. 24, n. 2, p. 439, 2011. Disponível em: https://seer.ufrgs.br/CadernosdoAplicacao/article/view/35471/23025. Acesso em: 20 de out. de 2013.

BERLEZE, Adriana; VIEIRA, Lenamar; KREBS, Ruy. Motivos que levam crianças para a prática de atividades motoras na escola. Revista da Educação Física/UEM, v. 13, n. 1, p. 99-107, 2002. Disponível em:

https://www.researchgate.net/publication/277164207 motivos que levam_criancas_a pratica de atividades motoras_na escola. Acesso em: 13 de setembro 2016. 
BRANDOLIN, Fábio; KOSLINSKI, Mariane; SOARES, Antônio Jorge. A percepção dos alunos sobre a Educação Física no Ensino Médio. Revista da Educação Física/UEM, v. 26, n. 4, p. 601-610, 2015. Disponível em: http://www.periodicos.uem.br/ojs/index.php/RevEducFis/article/view/29836/15612. Acesso em: 10 de jan de 2017.

BRASIL. Parâmetros Curriculares Nacionais: Educação Física. Brasília: MEC/SEF, 1997. Disponível em: http://portal.mec.gov.br/seb/arquivos/pdf/livro07.pdf. Acesso em: 09 de ago. de 2012.

BRASIL. Base Nacional Comum Curricular. Brasília: MEC, 2017. Disponível em: http://basenacionalcomum.mec.gov.br/abase/. Acesso em: 5 de jan. de 2018.

COUTO, Cremilda. Escola em ciclos: o desafio da heterogeneidade na prática pedagógica. In: Reunião Anual da ANPED, 32, 2009, Caxambu/MG. Anais eletrônicos...Caxambu/MG: ANPED, 2009. Disponível em: http://32reuniao.anped.org.br/arquivos/trabalhos/GT13-5366--Int.pdf. Acesso em: 05 de mar. de 2012.

CRESWELL, John; PLANO CLARK, Vick. Pesquisa de métodos mistos. 2ed. Porto Alegre: Penso, 2013.

DARIDO, Suraya Cristina. A Educação Física na escola e o processo de formação dos não praticantes de atividade física. Revista Brasileira de Educação Física e Esporte, São Paulo, v. 18, n. 1, p. 61-80, 2004. Disponível em: https://www.revistas.usp.br/rbefe/article/view/16551/18264. Acesso em: 21 de mai. 2012.

EINSFELDT, Rafaella; LETTNIN, Carla. La (Des)seriaciónenEducación Física: uma propuesta de aceptación a estudiantes de Escuela Media. Lecturas: Educación Física Y Deportes, v. 23, n.245, p. 34-48, 2018. Disponível em: https://www.efdeportes.com/efdeportes/index.php/EFDeportes/article/view/645. Acesso em: 09 de dez. de 2018.

FONSECA, Denise; MACHADO, Roseli. Educação Física: (re)visitando a Didática. Porto Alegre: Sulina, 2015 .

GALLAHUE, David; OZMUN, John. Compreendendo o desenvolvimento motor: bebês, crianças, adolescentes e adultos. 3. ed. São Paulo: Phorte, 2005.

LEITÃO, Marcelo; SILVESTRE, Mirian; BEZERRA, Manuel; LACERDA, Yara. Implicações sociais e autonomia em educação física escolar: uma abordagem construtivista do movimento. Revista Brasileira de Ciência e Movimento. v. 19, n. 03, p. 76-85, 2011.Disponível em:https://portalrevistas.ucb.br/index.php/RBCM/article/view/1881/2042. Acesso em: 18 de jun de 2017.

LETTNIN, Carla. (Re)pensando a estrutura funcional da Educação Física para o Ensino Médio com o intuito de atender a diversidade. Revista Mineira de Educação Física, Viçosa, Edição Especial, v. 7, n. 1, p. 646$657,2012$.

LETTNIN, Carla. (Des)seriação da Educação Física no ensino médio como proposta de contribuições à saúde: visão de alunos e professores, 2013. Tese (Doutorado em Educação) - Faculdade de Educação, Universidade Católica do Rio Grande do Sul, Porto Alegre, 2013.

LETTNIN, Carla; DAVOGLIO, Tárcia; STÖBAUS, Claus; CID, Luis. Questionário de Necessidades Psicológicas Básicas em Educação Física (QNPB-EF): validação preliminar brasileira. In: II Congresso Íbero-Americano / III Congresso Luso-Brasileiro de Psicologia da Saúde, Actas... Faro- PT: UAlg, v. 1, p. 1-12, 2013. Disponível em:

http://repositorio.pucrs.br/dspace/bitstream/10923/8599/2/questionario de necessidades psicologicas basica s_em educacao fisica qnpb ef validacao preliminar_brasileira.pdf. Acesso em: 18 de out. de 2015.

LETTNIN, Carla; JESUS, Saul; STOBÄUS, Claus. A Educação Física em direção ao bem-estar discente: reflexões de professores e graduandos portugueses sobre a (des)seriação no Ensino Médio.

EFDeportes.com, Revista Digital. Buenos Aires, v. 17, n. 175, 2012. Disponível em: 
http://www.efdeportes.com/efd175/a-educacao-fisica-sobre-a-des-seriacao-no-ensino-medio.htm. Acesso em: 05 de ago. de 2015.

MINAYO, Maria. Pesquisa social:teoria, método e criatividade. 18 ed. Petrópolis: Vozes, 2001.

MORAES, Roque. Uma experiência de pesquisa coletiva: Introdução à análise de conteúdo. In: GRILLO, Marlene C.; MEDEIROS, Marilú F. (Orgs). A construção do conhecimento e sua mediação metodológica. Porto Alegre: EDIPUCRS, 1998.

MOUTÃO, João; ALVES, Susana; CID, Luis. Contributo da teoria da autodeterminação na predição da vitalidade e adesão ao exercício físico. Revista Gymnasium- edição especial - XII Jornadas Sociedade Portuguesa de Psicologia do Desporto, v. 3, n. 1, p. 13-34, 2012. Disponível em:

https://revistas.ulusofona.pt/index.php/gymnasium/article/view/2537. Acesso em: 12 de maio de 2019.

NTOUMANIS, Nikos. A prospective study of participation in optional school psysical education using a self-determination theory framework. Journal of Educational Psychology, Washington, v. 97, n. 3, p. 444-453, 2005. Disponívelem: https://doi.apa.org/doiLanding?doi=10.1037\%2F0022-0663.97.3.444. Acesso em: 09 de fev. de 2012 .

PAIS-RIBEIRO, José. A importância da qualidade de vida para a psicologia da saúde. In: CRUZ, José; JESUS, Saul N. de; NUNES, Cristina. (Coord.). Bem-estar e qualidade de vida: contributos da psicologia da saúde. Portugal: Textiverso, 2009.

PIZANI, Juliana; BARBOSA-RINALDI, Ieda; MIRANDA, Antônio Carlos; VIEIRA, Lenamar. (Des)motivação na Educação Física escolar: Uma análise a partir da teoria da autodeterminação. Revista Brasileira de Ciências do Esporte. Maringá, v. 38, n. 3, p. 259-266, 2016. Disponível em: https://reader.elsevier.com/reader/sd/pii/S0101328915001286?token=4F597C16CF92C4792826A078F98B0 4B241AE860B2314AE30B388B0DAF0C38D957FE255D3377509DAC0F037E740C50355. Acessoem: 03 de jan 2017.

RYAN, Richard; DECI, Edward. Self-determination theory and the facilitation of intrinsic motivation, social development and well-being. American Psychologist, Washington, v. 55, n. 1, p. 68-78, 2000. Disponível em:https://doi.apa.org/doiLanding?doi=10.1037\%2F0003-066X.55.1.68. Acesso em: 04 de abr. de 2012.

RYAN, Richard; DECI, Edward. Active human nature: Self-determination theory and the promotion and maintenance of sport, exercise and health. In: HAGGER, Martin; CHATZISARANTIS, Nikos. (Eds.). Intrinsic motivation and self-determination in exercise and sport. Champaign-Illinois: HumanKinetics, 2007.

SILVA, Glauber; BERGAMASCHINE, Rogério; ROSA, Marcela; MELO, Carolina; MIRANDA, Renato; BARA FILHO, Maurício. Avaliação do nível de atividade física de estudantes de graduação das áreas saúde/ biológica. Revista Brasileira de Medicina do Esporte, v. 13, n. 1, p. 39-42, 2007. Disponível em: https://www.scielo.br/scielo.php?script=sci arttext\&pid=S1517-86922007000100009\&lng=pt\&tlng=pt. Acesso em: 07 de abr. de 2012.

SILVA, Rodrigo; MATIAS, Thiago; VIANA, Maick; ANDRADE, Alexandro. Relação da prática de exercícios físicos e fatores associados às regulações motivacionais de adolescentes brasileiros.Motricidade, v. 8, n. 2, p. 8-21, 2012. Disponível em:

https://www.researchgate.net/publication/262748580 Relacao da pratica de exercicios fisicos e fatores a ssociados as regulacoes motivacionais de adolescentes brasileiros. Acessoem: 08 de jul de 2013.

VAN DER KAAP-DEEDER, Jolene; DE HOUWER, Jan; HUGHES, Sean; SPRUYT, Adriaan; VANSTEENKISTE, Maarten. The development and validation of an implicit measure of competence need satisfaction. Motivation and Emotion, v 42, p.615-637, 2018. Disponívelem:

https://link.springer.com/article/10.1007/s11031-018-9685-3. Acesso em: 27 de out. de 2018. 


\section{NOTAS DE AUTOR}

\section{AGRADECIMENTOS}

Agradecemos ao Núcleo de Assessoria Estatística da Universidade Federal do Rio Grande do Sul pelas orientações durante o processo de tratamento dos dados.

\section{CONTRIBUIÇÃO DE AUTORIA}

Ambos os autores contribuíram em todas as etapas, desempenhando todos os papeis necessários para a produção do texto.

FINANCIAMENTO - Bolsa PIBIC/CNPq.

CONSENTIMENTO DE USO DE IMAGEM - Não se aplica.

\section{APROVAÇÃO DE COMITÊ DE ÉTICA EM PESQUISA}

Este estudo faz parte de um protocolo de pesquisa mais amplo que teve aprovação na comissão científica da PUCRS - protocolo de pesquisa n. 38/2011 e aprovação na Plataforma Brasil - parecer n. 184.410 .

\section{CONFLITO DE INTERESSES}

Declaramos que nessa produção não há conflitos de interesses pessoal, comercial, político, acadêmico ou financeiro.

\section{LICENÇA DE USO}

Os autores cedem à Motrivivência- ISSN 2175-8042 os direitos exclusivos de primeira publicação, com o trabalho simultaneamente licenciado sob a Licença CreativeCommonsAttribution Non-Comercial ShareAlike (CC BY-NC SA) 4.0 International. Esta licença permite que terceirosremixem, adaptem e criem a partir do trabalho publicado, desde que para fins não comerciais, atribuindo o devido crédito de autoria e publicação inicial neste periódico desde que adotem a mesma licença, compartilhar igual. Os autores têm autorização para assumir contratos adicionais separadamente, para distribuição não exclusiva da versão do trabalho publicada neste periódico (ex.: publicar em repositório institucional, em site pessoal, publicar uma tradução, ou como capítulo de livro), com reconhecimento de autoria e publicação inicial neste periódico, desde que para fins não comerciais e compartilhar com a mesma licença.

\section{PUBLISHER}

Universidade Federal de Santa Catarina. Programa de Pós-Graduação em Educação Física. LaboMídia - Laboratório e Observatório da Mídia Esportiva. Publicado no Portal de Periódicos UFSC. As ideias expressadas neste artigo são de responsabilidade de seus autores, não representando, necessariamente, a opinião dos editores ou da universidade.

\section{EDITORES}

Mauricio Roberto da Silva, Giovani De Lorenzi Pires, Rogério Santos Pereira.

\section{EDITOR DE SEÇÃO}

Juliano Silveira.

\section{REVISÃO DO MANUSCRITO E METADADOS}

João Caetano Prates Rocha; Keli Barreto. 


\section{HISTÓRICO}

Recebido em: 12 de agosto de 2020.

Aprovado em: 23 de novembro 2020. 